somewhat complicated electric system designed to get rid of the overhead wire, the car itself carrying a length of wire overhead sufficiently long to make connection between a series of poles and studs in the paving. The general opinion of all the electrical engineers who took part in it, both British and American, seemed to be that for smaller towns with comparatively un. crowded streets, and for the outlying roads of great cities, especially those extending into residential suburbs (most of the existing tram-lines in London run mainly on such roads), the overhead trolly wire system was at present, at any rate, the only possible system ; its great cheapness and simplicity, as compared with all conduit systems, practically gave it a monopoly. For the main business streets of great cities, however, if street tramways are to be allowed at all, a somewhat doubtful point, then some system which abolishes both the overhead wire and the open conduit seems the ideal one. At present no satisfactory one has yet been brought into use. One thing is certain : every British visitor to Toronto, after experiencing the comfort and value of the quick, well-lit, and frequent car service of that city, will return to the Old Country an ardent advocate of the adoption of electric traction on our street-cars. The contrast between this splendid system of street-cars and our slow, wretchedly-lit system is so great, that one can only wonder that we have put up with the latter so long. The abolition from our streets of the thousands of horses required by tram. cars and busses, is of itself a great argument in favour of electric traction; the filth of the streets would at once be sensibly reduced, and we should be spared the pain of seeing the sightnow only too common in our streets-of overworked horses struggling painfully to start overloaded cars and busses.

The bugbear of the hideousness of the overhead wire is, let us hope, at last being seen in its true light; in any street of Toronto, where the overhead wires of the car-system were the only ones, they were inconspicuous and almost unnoticeable; the people responsible for the frightful mass of wires and poles which disfigure the leading streets of American cities, are not the tramway companies, but the telegraph, telephone, and electric light companies. The overhead wire tramway poles would be practically unnoticeable in any street of an English city; and most certainly,there are very few, if any, streets where they would be obtrusive, or do anything to increase the already, alas, existing prevalent ugliness.

The conditions of modern city life, the absolute necessity of the worker living-if he is to secure a healthy cheap dwelling-miles from his place of work, render imperative some system of cheap and efficient transport through the streets. Though our underground electric railways may do something towards solving this problem in London, still, in the other cities, and in London itself, the street-car must be the chief method adopted; and it is monstrous that we should still be compelled to put up with our antiquated and inefficient system of horse traction, while every little town of mushroom growth in America has already solved the problem, and given its inhabitants the most perfect systems of street traction. Liverpool is to show the way; let us hope, that in a year or two the electric street railways of great Britain will increase so rapidly that we shall be able to compare them, as regards mileage, with the thousands of miles already in use across the Atlantic. If the meeting of the Association in Toronto should hasten on this desirable social improvement, it will not have been in vain, and will be looked back to with pleasure by all those anxious to make life in our great cities more healthful and more perfect.

\section{THE WORK OF PASTEUR AND THE MODERN CONCEPTION OF MEDICINE.}

$M R$. PREsident, Ladies, and Gentlemen,-It is not $M$ without emotion that I rise to address this learned assembly. I know, indeed, that $\mathrm{I}$ am addressing men who are not my fellow citizens, but among them are some, enfants de notre vieille natzon Gauloise, who have the same mother tongue as we ; they speak from childhood our beloved French language, they are thus a little more than my fellow citizens, for they are my compatriots, and I feel myself animated by a truly fraternal affection for them; and as to my English colleagues, they have given evidence of so much good will and of a courtesy so

1 An address delivered before the British Medical Association, at Montreal, by Prof. Charles Richet. (Reprinted from the British Medical NO. 1456 , VOL. 56$]$ delicate, that I need make no great effort to assure them of my gratitude. In one word, although a stranger I seem to be among friends.

I am somewhat troubled, also, because I am addressing medical men and am speaking before a medical congress. Now, although I belong in some small degree to the great medical family, since my father has conferred honour upon the profession of medicine by his labours and by his works; and although I have the great honour to be the delegate of the Faculty of Medicine of Paris, yet I am not a medical man, and a physiologist displays some temerity in venturing to speak before you on medical matters.

The Reconciliation of Medicine and Science.

Still I have an excuse. It is this, that I desire to attempt to bring about a complete reconciliation between medicine and science. It may seem that this is a commonplace, and that any such attempt would be unnecessary. But it is not so, gentlemen. We might find, perhaps, somewhere-not, I am sure, in this assembly-medical men ready, unhesitatingly, to assert that there is discord between medicine and science, and that all those sciences which are called auxiliary--physics, chemistry, physiology-are impedimenta with which the clinician has nothing to do. Yes, there are to be found in the world medical men, among them even men of high attainments, who are ready still to say: "What have I got to do with your experimental science? Observation of the sick and clinical study are worth more than all your clever experiments, and it is not from laboratories that the means of curing disease can come." Such an opinion appears to me to be erroneous, and I would with all the energy which I possess help to upset it. I hold that it is by experimental science alone that medicine has made and can make progress. It will suffice to describe the work of Pasteur, my illustrious master, in order to give' you a convincing demonstration of this.

I shall not be contradicted when I say that the value of this work is greater than all that the history of medicine has given us since the commencement of our era. Through his labours everything has been renewed, regenerated, and, thanks to him, medicine has made more progress in twenty years than had been made previously in twenty centuries.

The Life-Work of Pasteur.

Louis Pasteur was born at Dôle in the Jura in $182 \mathrm{r}$, and at the beginning of his career gave himself up to the study of chemistry. He became deeply interested in a difficult and important problem-molecular dissymmetry. Here was a question in pure chemistry which would seem to take us very far from medical questions, but it was to lead Pasteur directly to the study of fermentations. If a solution of tartaric acid (in the form of tartrate) be left untouched, a change occurs after some time in the chemical constitution of the liquid, which before Pasteur's time had been overlooked. The original solution had no action on polarised light, but after fermentation this same solution has become capable of deflecting polarised light. Pasteur explained this phenomenon by showing that the origina tartaric acid is a mixture of an acid deviating light to the right with an acid deviating it to the left, and that a process of partial decomposition takes place; one of the acids is destroyed and the other is not altered, so that the action upon polarised light, previously masked by the mixture of the two acids, becomes evident. Here we have a fundamental experiment. It is told how when the young Pasteur desired to show it to Biot, that great physicist, who had discovered the phenomena of polarisation, the old savant wrasped the trembling hand of the young man, and, before beginning the optical examination of the crystals submitted to him by Pasteur, said to him with tears in his eyes, "Mon cher enfant, I have loved science so much, that in face of the beautiful experiment which you relate to me I cannot prevent myself from being deeply moved."

The explanation given of this phenomenon at that time was that the tartaric acid was decomposed by fermentation. Men were then content to use this magic word, which appeared to explain everything, but which in reality told nothing at all. Neither Lavoisier, nor Liebig, nor Frémy had been able to discover its meaning, and were reduced to the theory of halforganised matter - a childish conception worthy of Paracelsus.

One of Pasteur's experiments, perhaps the most beautiful which he ever made, demonstrated the nature of this mysterious phenomenon. If a sugary solution of carbonate of lime 
is left to itself, after a certain time it begins to effervesce, carbnnic acid is evolved, and lactic acid is formed, which decomposes the carbonate of lime to form lactate of lime. This lactic acid is formed at the expense of the sugar, which disappears little by little. But what is the cause of this transformation of sugar into lactic acid? Well, Pasteur showed that the efficient cause of this chemical action was a thin layer of organic matter; that this layer of organic matter consisted of extremely small moving organisms, which increased in number as the fermentation went on. Their growth it is, then, which produces the phenomenon of the transformation of sugar of milk into lactic acid. If, for example, we take a sugary solution in which all pre-existing germs have been destroyed by heat, no lactic fermentation will take place. But if we introduce into this sterile liquid a small quantity of this layer of organic matter, such as can be obtained from any liquid in which normal lactic fermentation is taking place, we shall see the lactic acid again form rapidly in the new solution.

Let us dwell a little on this admirable experiment. Nowadays it seems to us so extremely simple that we can scarcely perceive its importance. It seems to us now, in 1897 , that from all time we must have known that an organic solution when heated was sterile, and that a germ would suffice to render it capable of fermentation. But this is a mere delusion. No, a thousand times no! This great fact of the generation of germs was absolutely unknown before Pasteur, and the method of sterilising liquids, and of their inoculation with spores, was revealed to us by Pasteur. It is the nature of great discoveries that they become popularised in a short time, and thus very quickly become elementary. A first year's medical student knows perfectly that which neither Lavoisier, nor Liebig, nor Frémy, nor any one before Pasteur had been able to perceive. We are always tempted to be ungrateful to great creators, for their creations pass rapidly into the domain of common knowledge. They become so simple that they cease to surprise us. We do not think of being grateful, and we forget the efforts which genius has had to make to wrest the truth from jealous nature. Gentlemen, let us not be ungrateful, let us remember that the recognition of the real cause of all fermentation (the development and germination of organised elements) dates from 1857 , and from the celebrated memoir of Pasteur upon lactic fermentation. A new world was then opened to science.

Nevertheless, this memoir of Pasteur's, containing one of the fundamental discoveries of the century, was not welcomed as it ought to have been. At first its importance was not understood, and afterwards absurd contradictions were opposed to it. A whole series of beautiful and decisive experiments was necessary to prove that there was no such thing as spontaneous generation, and that sterile liquids remained sterile indefinitely so long as no germs were introduced into them. Pasteur devoted six years (I857-1863) to the proof of the fundamental fact that "organic liquids do not alter until a living germ is introduced into them, and living germs exist everywhere."

\section{The Microbic Theory of Disease.}

A great step yet remained to be taken. This was to determine the evolution of these germs, not merely in vitro, but in the living organism. We to whom the idea of parasitism and microbic infection is now so familiar can scarcely conceive that it has not always been thus.

The microbic theory has become so ordinary, so popular, that we are tempted to believe that the part played by microbes was understood even in the times of Hippocrates; but I assure you that in truth this was not the case, and for long enough after Hippocrates the power of microbes was not known.

Pasteur, to whom, and to Sédillot and Littré, we owe the word "microbe," was the-first also to explain to us in his essay on the silkworm disease, published in 1867, the part they played in the production of disease. He proved that the bright corpuscles found in the bodies of diseased silkworms are living germs - a distinct living species, a parasite which can multiply and reproduce itself and disseminate the contagion.

It was therefore with painful astonishment that I heard Prof. Marshall Ward recently say that the discovery of the part played by micro-organisms in disease was due to Koch, and dated from 1876. Now, ten years before this, Pasteur had published his experiments on pebrine and facherie. Davaine had shown the part played by bacteria in anthrax infection, and the idea of infection and of contagion by microbes in the higher animals as well as in the lower had become a commonplace, not indeed in the medical world, but in all laboratories.

Thus, by successive steps, did the work of Pasteur develop in all its greatness and logic. In the first place, in order to elucidate a chemical problem, he studied tartaric fermentation; then he was led to study lactic fermentation, and he showed that they were biological phenomena. He then pursued the analysis of this phenomena with all its consequences, and was led to the conception that disease was due to the development of a parasite.

The normal living being follows out its course of growth without the development of any organic parasite in its tissues or in its humours. But if these humours or tissues happen to be inoculated with any organism capable of developing, then this small living thing multiplies, the higher organism is infected, and the whole body becomes, as it were, a culture fluid, in which the pathogenic microbe propagates itself, a centre of infection which scatters the disease by sowing the noxious germs whereever it goes. Thus arose the new conception, profoundly new not only for medicine but for hygiene-Disease is Parasitism. Thenceforth we understood the meaning of the words "infection" and "contagion," previously mysterious.

It is true that Pasteur did not discover all the microbes of all contagious diseases; but this is of small moment, since $h \epsilon$ was the first to discover that infection was a phenomenon of microbial parisitism. All those who after him have proved points of detail, however important or fundamental they may be, have but followed the path traced by the master. Whether they will or not, they are all the pupils of Pasteur, as those who follow the study of chemistry are pupils of Lavoisier.

The greatest of Pasteur's disciples, Robert Koch, although with some ingratitude he refuses to recognise his master, has only perfected certain points in technique and applied his ingenuity and his perspicacity to the solution of questions which, in spite of their practical importance, are still secondary. He has not, in fact, been able to do anything new except upon points of detail; all that is essential comes from Pasteur himself.

Need I say that this idea of the microbe, of the parasite, has become the basis of medicine. If we take up treatises on pathology written before this prodigious revolution, we shall be astonished by the insignificance and the nothing. ness of these very ancient books. Yet they are not really very old ; they are dated 1875 or 1880 ; but as one reads them it seems as though several centuries must have intervened between these venerable writings and modern books. I know an excellent article on tuberculosis written in 1878 , before the microbe of tuberculosis had been discovered. Well, this article belongs to another age; it belongs no longer to medicine, but to the history of medicine, for it swarms with mistakes and incredible errors with regard to pathological anatomy, etiology, prophylaxis, treatment-in fact, from every point of view.

In ten years medicine has been entirely overturned and remade. It is being re-made every day. Every day brings some new discovery in matters of detail ; but the great principle is always there, and it must always be attributed to the one initiator.

This is not all. Another new and great discovery was to be made by Pasteur himself, and to constitute the supreme development, the culminating point, as it were, of his life's work. This is the principle of vaccination. By a series of researches, admirable for their precision, Pasteur proved that the pathogenic microbe could be attenuated-that is to say, rendered incapable of causing death. But, though this microbe does not cause death, yet it can produce the disease, a disease sometimes so attenuated as to be almost imperceptible. Now the living being which has suffered from this attenuated disease is protected against its more serious forms, and, borrowing the word consecrated by the immortal discovery of Jenner, Pasteur said that we have here "vaccination."

Fermentation, infection, contagion, vaccination; here in four words we have the work of Pasteur. What more need I say? Do not these four words possess, in their simplicity, unequalled eloquence.

Can any one longer maintain that the progress of medicine is not due to experimental science? Does not all this knowledge of microbes and of the part which they play in disease imply, immediately and necessarily, immense progress in therapeutics

NO. I 456 , VOL. 56$]$ 


\section{Antiseptic Surgery.}

To take but one example, I will cite the application of microbial theories to surgery.

There was a time when erysipelas, purulent infection, and hospital gangrene decimated those upon whom operations had been performed, when puerperal infection claimed a terrible number of victims. It seems to us nowadays that the medical profession before I 868 were blindfolded, and that their blindness was almost criminal. These are now no more than historic memories. A sad history, doubtless, but one which we must look at coolly in order to understand what science can do for medicine. Left to their own resources, practitioners of medicine during long centuries could do nothing against erysipelas, against purulent infection, against puerperal infection; but, basing itself upon science, surgery has been able to triumph over these odious diseases, and to relegate them to the past.

Let me here introduce a reminiscence. When on the occasion of his jubilee, a great celebration was prepared for Pasteur in the Sorbonne, in the presence of the leading men of science of the world, there was a moment when all hearts were softened -the moment when the great surgeon who was first to perceive how to apply to the practice of his heart the theory of pathogenic parasites, when Lord Lister drew near to Pasteur and gave him a fraternal embrace. These two great benefactors of humanity, united in their common work, afforded a spectacle never to be forgotten, a striking reconciliation of medicine with science.

But the apogee of the glory of Pasteur was the discovery of the new treatment of hydrophobia. No one of his scientific conquests was more popular, and from France and from the whole world there arose a long cry of admiration. Perhaps in the eyes of biologists this discovery possesses less importance than his labours with reference to the fermentations and to vaccination, but for the public this was the chief part of Pasteur's work. And men of science also were forced to admire the scientific courage of Pasteur, who, putting aside the precise methods which he had taught and discovered, knew how to devise new methods to meet the exigencies of the circumstances, and how to put them victoriously into practice.

Thus was finished the work of Pasteur. He was spared to take part in the triumph of his ideas, and to be a witness of his own glory. If, like so many creators, he had sometimes in his earlier days known conflicts and hatreds and petty quarrels and foolish objections, nevertheless he had not to deplore the ingratitude of mankind. He died full of honours, surrounded by admiration, respect, and love. For him posterity had already commenced when he died.

\section{The Union of Medicine and Science.}

And now let us turn back to consider the indisputable union of medicine and of science. This, in fact, is what ought to strike us in the work of Pasteur. It is not only in general biology and in the progress of our knowledge that his work is great; it is still more in its immediate practical applications. The great biologists of our century, Lavoisier, Claude Bernard, Darwin, have, without doubt, left behind them work which by reason of its conquest of new truths is not inferior to the work of Pasteur, but these new truths do not lead to any such immediate application as antisepsis, the treatment of hydrophobia, anthrax-vaccination, or the prophylaxis of infectious diseases. Pasteur was not only a man of science, he was also a philanthropist, and there is scarcely one who can be compared with him as a benefactor of suffering humanity except Jenner, who found out how to preserve thousands and thousands of human beings from the most hideous of all diseases.

Further, Pasteur brought back medicine into the true way of science. Even after Magendie, Müller, Schwann, and Claude Bernard, it might still have been asked whether all these experiments establishing so many important truths had really been of any advantage for the relief of the sick. To discover, as did Schwann, that living beings are an aggregate of cells; to prove, as did Claude Bernard, that the liver forms sugar; to establish, as did Darwin, that living species can be transformed by the influence of long-accumulated variations in the environments-these are admirable pieces of work, but work in pure science which had not any immediate therapeutic results. Strictly speaking, then, it was possible to maintain that clinical medicine did not derive any benefit from such investigations. I do not for a moment believe that this opinion had a shadow of a foundation, but before the time of Pasteur it was not so absurd as it has become since Pasteur. Since Pasteur no man can, without incurring the charge of monstrous ineptitude, refuse the rights of citizenship in medicine to experiment and to biology.

And to speak the truth, men of science and biologists, as though their ardour had been redoubled by the renovation of medical ideas, have during these last ten years made discoveries which have introduced into medical science new elements which clinical observation alone had been absolutely incapable of discovering. I will cite a few examples-the action of the thyroid gland, the Röntgen rays, pancreatic diabetes, and serum therapeutics.

\section{THYROID IN THERAPEUTICS.}

Physiologists had shown long ago that the ablation of the thyroid gland led to serious results. Schiff had proved this as long ago as 1857 , but the explanation of the phenomenon did not become clear until Claude Bernard, but especially Brown. Séquard, had demonstrated the existence of internal secretions of glands pouring into the blood their products which probably neutralise certain toxic substances. This very naturally led Vassale and Gley to inject into animals from whom the thyroid gland had been removed the juice of the thyroid, and thus prolong their lives. The therapeutic conclusion to be drawn was obvious, namely, to treat the unfortunate subjects of cretinism or of diseases of the thyroid gland by injection of extracts of the thyroid body. You know that the result has been most happy.

This new treatment was a true experiment, and as is the case with so many experiments, the actual result has been a little different from that which was expected. The ingestion of thyroidin is not only a means of curing goître and cretinism, but is only a treatment, sometimes remarkably efficacious, for obesity.

\section{The Röntgen Rays.}

The discovery of the Röntgen rays excited general enthusiasm, and as a matter of fact it is one of the greatest conquests of contemporary physics. Most assuredly medicine had nothing to do with it. The research was made and the success was obtained in a physical laboratory. Now you are not unaware that these Röntgen rays have been called to play a part, if not in the treatment at least in the diagnosis of diseases-a part the importance of which goes on increasing from day to day. Physicists have discovered the principle, it is for medical men to follow up its application.

\section{Pancreatic Diabetes.}

The existence of pancreatic diabetes was suspected vaguely by a clinical physician, Lancereaux; but the means which clinical medicine and pathological anatomy placed at his disposal did not give him the power to solve the problem. In spite of his perspicacity, he could do no more than note a certain correspondence between diabetes and lesions of the pancreas. How could more have been learnt if we had not the resource of 'experiment? Two physiologists, Mering and Minkowski, have had the good fortune to show that ablation of the pancreas determines glycosuria, to show that there is a pancreatic diabetes, and they have studied its various conditions with great ability.

I come now to serum therapeutics, a direct consequence of the labours of Pasteur. This is a mode of treatment born of the experimental method alone. Here, again, science has done for the art of medicine that which clinical observation, left to its own resources, could never have accomplished.

Permit me now to show how serum therapeutics is derived directly from physiology and experiment, and pardon me if I am forced to speak of my own work; I shall do so I hope without any vanity. I know very well that we always owe to our predecessors and to our rivals much more than our pride admits, and that the experiments and the ideas which succeed are not always those which have been conceived most methodically

About I887 M. Chauveau had shown that French sheep could contract anthrax, and that they are very easily infected by the bacillus anthracis, the microbe of anthrax, if small quantities of the bacillus be injected under the skin. But Algerian sheep seem to be safe from the disease. In vain is the bacillus anthracis injected into them; they do not contract

$$
\text { NO. I } 456 \text {, VOL. 56] }
$$


anthrax. They are refractory to this disease and possess a remarkable immunity to it. Having refiected on this strange fact I framed the hypothesis that the cause of the immunity of the Algerian sheep, which are absolutely similar from the anatomical and zoological point of view to French sheep, depended upon chemical substances contained in the blood, and that in consequence we might hope to confer immunity on French sheep by transfusing into them the blood of the Algerian sheep. It is, however, difficult to make experiments on sheep. Therefore, with my friend Héricourt, who has been throughout these researches my tireless fellow worker, I took animals of two different species, the common victims of physiologists-rabbits and dogs.

Just at that time we had been studying a microbe nearly related to the staphylococcus albus, the staphylococcus pyosepticus, which in rabbits produces enormous subcutaneous swellings when injected under the skin and causes death in twenty-four to thirty-six hours. The dog, on the other hand, seems to be almost refractory to inoculation with this microbe. We therefore attempted to transfuse the blood of the normal dog into rabbits by intravenous injection, but this operation did not succeed, for the transfusion of dog's blood into the veins of the rabbit even in a dose of only Io gm. rapidly causes death.

In then occurred to us to resort to peritoneal transfusion in place of intravenous transfusion. In this way we were able to introduce into the organism of the rabbit 50 or $60 \mathrm{gm}$. of dog's blood, and had the good fortune to see the experiment succeed completely. Rabbits transfused with the blood of the normal dog survived the inoculation of the microbe for four or five days, and rabbits transfused with the blood of a dog vaccinated against the microbe did not die, and were in fact hardly ill at all.

This experiment, which was made on November 5, I888, is, as it seems to me, the very basis of serum therapeutics; it in fact proves that the blood of animals refractury to a disease contains chemical bodies which counteract the effects of the specific pathogenic microbe of the disease. We understood its importance from the first, and having established the general pathological principle, we resolved to apply it to a disease of man.

For several days, then, Héricourt and I debated the question whether we should experiment with one or other of the three diseases-anthrax, diphtheria, or tuberculosis. Unfortunately we decided for tuberculosis. Its microbe is easily cultivated, and, as you know, it produces greater ravages among men and animals than any other disease. We set to work at once, but, as you will understand, time was required before we could obtain definite results. Still, in a year's time we were able to show that the injection of dog's blood into rabbits retarded enormously the development of tuberculosis. It was, nevertheless, necessary to pass from experimental physiology to human therapeutics. Taking advantage of an observation of Bouchard's to the effect that the serum of refractory animals is as active as the whole blood, we were able to inject the serum in tuberculous diseases. The first sero-therapeutic injection was made by us on December 6, 1889 .

At inrst we had for a space great hope. Yes, in truth, for several weeks we believed that we had discovered the heroic treatment of tuberculosis. For several weeks the various patients that we had under treatment found that their strength was renewed, that their appetite returned, that their weight increased, and that cough and expectoration disappeared almos completely. But, alas, it was no more than a transient improvement. A month or a month and a half later the pitiless disease resumed its course, and the sero-therapeutic treatment turned out to be inefficacious. Happily, while by the most diverse plans we were in vain searching for a method of treating tuberculosis by serum, a German experimenter, Behring, after studying the effects of the serum of refractory animals upon diphtheria, showed (in 1892) that this serum is wonderfully efficacious in the treatment of the disease. He applied the serum method of treatment not only to diphtheria, but also to tetanus, and, at first in animals and afterwards in man, he obtained results which were really marvellous. Gentlemen, you know the rest, and I need not tell you that this sero-therapeutic method, improved and popularised by Roux in 1894 , is now a treatment without compare. The statistics on this head are absolutely conclusive. The mortality of diphtheria, which was 45 per cent., has fallen to 15 per cent. That means for the city of Paris alone an annual

$$
\text { NO. I456, VOL. 56] }
$$

saving of about 1000 human lives; for the whole of France nearly 10,000 lives. We may take the same proportion for Italy, Germany, England, the United States, Canada, and Russia, and may estimate the number of infants which serum therapeutics snatch from death at about 50,000 .

In other diseases the results of serum therapeutics have been much more open to criticism, and it would be necessary in order to arrive at a satisfactory conclusion to discuss them in detail. I cannot attempt to do this here, for it would be an abuse of your patience. I will content myself by venturing the opinion that serum-therapy has not said its last word. The organism is endowed with a marvellous power of resisting the poisons secreted by microbes. It sets to work in its turn to secrete counter poisons which neutralise the poisons secreted by the microbe. The antitoxins of the organism combat the toxins of the parasite, and in the future the art of serum therapeutics will be to seek in these resisting organisms the antitoxins fabricated by their cells.

\section{Medicine and Experimental Science.}

Thus on whatever side we turn we find that medicine has always been guided by experimental science. By experiment and by science it is compelled to march forward. This was true in the time of Harvey, for that immortal physiologist had to meet the opposition of physicians. This was true also in the time of Lavoisier, when by a few decisive experiments he proved the chemical nature of the phenomena of life. But how much more true is it at the present time since Pasteur has by experiment laid open a whole world, and has warranted us in conceiving the widest hopes for the future of medicine?

The parts of the man of science and of the physician are very different. The physician ought to be conservative, applying methodically the teaching and the precepts which he has received. He has no right to experiment upon his patients, ot to permit human life or human suffering to be risked on fantastic theories. But the man of science ought to be a revolutionist. He ought not to be content with the doctrines which he has been taught. The opinion of the master ought to be but a light weight upon his mind. $\mathrm{He}$ ought to seek on every hand for facts which are new and even improbable. Darwin says somewhere that he had made the experiments of a fool, and often it is right to attempt that which appears contradictory to all the most received and classical opinions. Without this spirit of adventure, without this scientific daring which opens up new horizons there is no progress.

The task of the explorer or of the pioneer is not that of the physician. He ought to be careful to keep himself abreast of all scientific progress in order that his patients may have the benefit of it, but he cannot advance the progress of science, save within restricted limits. Having no right to experiment, he is almost powerless to solve the difficult problems which arise.

It is the duty of the chemists, the physicists, and above al; the physiologists, to guide medicine into the new ways. They have not to take the heavy responsibility of a human life upon their shoulders, and nothing ought to check their audacity. You, gentlemen, have not the right thus to be audacious: yol need prudence and moderation, and, convinced as I am of the power of experimental science, I still think that the applications which the chemists and the physiologists suggest to you should only be accepted with considerable caution. It costs us nothing, after a few experiments which have succeeded fairly well, to say to the physician, "Try that on your patients." You know very well that our responsibility is nil, and that the ancient axiom primo non nocere, an axiom which ought to be your strict rule of conduct, does not in any way apply to us. You see, therefore, that it would be unjust to make it a matter of reproach to physicians and surgeons that they have not made great scientific discoveries. This is not their mission. It is theirs to relieve human suffering, and to seek among new scientific truths that one which is most proper to relieve or to cure the sick.

Nor can I understand how any one should have wished to create an antagonism between medicine and science. $\mathrm{T}_{0}$ suppose that they are in contradiction is to show that we understand nothing about either the one or the other. It is not reasonable to assert that the one is superior or inferior to the other; they are different in their means and in their ends. They are mutually complementary, and both are equally necessary. 
If I were ill most assuredly I would not seek the assistance of a chemist, or of a physiologist, and medicine is not to be learned from the books of Claude Bernard or of Pasteur. Clinical instruction is necessary, such as long observation of patients alone can furnish. Prophylaxis, diagnosis, prognosis, therapeutics are not to be learned in scientific books. Something else is necessary-observation, long, patient observation, the old Hippocratic observation, without which there can be no good physician. Young students must be guided in the examination of patients by experienced practitioners, and no one, I presume, would be guilty of the folly of proposing to replace the clinical ward by the laboratory.

But without laboratories the clinical department must remain incapable of scientific advance, and this condition of stasis is assuredly undesirable; for in spite of all the progress which has been made, much yet remains to be done. Are not tuberculosis and cancer, for example, the disgrace of medicine? I appeal to all medical men here present. Is there any one of you, gentlemen, who in the presence of such painful modes of death does not feel himself humiliated to the bottom of his soul by his powerlessness?

Well, this feeling of our present powerlessness against disease ought to stimulate us to work. The work to be done is enormous, and we must none of us grow weary of our task. We physiologists must seek new facts, we must seek and seek again, seek always without being afraid of the boldest hypothesis, and without putting any limit to our audacity, without troubling our heads as to the practical consequences which may flow from our discoveries, having only truth-divine truth - for our object. As for you, gentlemen, it is your duty to follow with the warmest interest both the general effect and the detailed results of biological discoveries in order to attempt to find some practical application for them. From this unceasing collaboration progress will be born. But it is necessary that men of science and physicians should both be animated with these two governing sentiments - faith in science and love of man.

\section{UNIVERSITY AND EDUCATIONAL INTELLIGENCE}

THE Athenaum says that a proposal is being considered to establish at Swansea, as a great manufacturing centre, a branch University College in association with either Aberystwith or Cardiff, as the Newcastle College is associated with Durham. The suggestion is that scientific and technical courses might be taken at Swansea in preparation for the Welsh University degree.

A SPECIAL course of instruction in electro-chemistry will be given during the coming session at the City and Guilds Central Technical College. The course will include practical instruction in electro-deposition, the use of the electric furnace, dynamos, transformers and accumulators. A great part of the time of the students attending this course will be devoted to electro-chemical research and the study of electro-chemical action. Candidates for admission will be required to submit evidence of having a general knowledge of physics and chemistry and of having been specially trained in one of these subjects.

A LONG article and a leader in yesterday's Times calls attention to the growth and present position of Higher-Grade Board Schools, of which there are about sixty now in the country, most of them containing over 500 scholars, while several have between 1000 and 2000 . It is pointed out that schools of this kind are an organic growth, and have not come into existence, like so many technical classes, because a public body suddenly found itself endowed with money which it did not understand how to spend. Boys and girls are eligible for admission into the highergracie schools after passing Standard VI. The course of instruction must include science, mathematics, drawing, manual instruction, English subjects, and at least one modern language. Science must be taught by means of laboratory instruction ; and all subjects taught must be submitted to inspection. The course prescribed extends over four years, and during the first two years grants are not paid on individual successes in examinations, but are paid as capitation grants, the amount of which depends on the efficiency of the teaching, the school equipment, and the average attendance. The Department of Science and Art further insist that classes shall not be allowed to contain many more than thirty students, and for practical work they fix the absolute maximum at twenty-five. These rules have made it possible to give in higher-grade schools a thoroughly satisfactory general education, in place of the one-sided education that was formerly given, From their very birth higher-grade schools have had to encounter bitter and determined opposition. Opposition came in the first place from the ratepayers, but the main opposition comes now from small endowed schools, which are beginning to feel their competition, and from those persons who wish to see secondary education placed under county councils, and find that in large towns School Boards are already in the field. So far as the actual competition is concerned, it is, perhaps, to be regretted that a grammar school should be steadily emptied of its students to swell the numbers of an already overfull higher-grade school. When this happens there is, however, one way to stop it. Let the grammar school bring itself to that state of efficiency which has been forced upon the higher-grade school by the hostile public criticism it has had to meet, and the public inspection to which it has all along been submitted. This is the advice given both in the article and the leader in the Times. It is also pointed out that the fact that higher-grade schools have, in some places, half-emptied local secondary schools, so far as it is due to the better and more practical character of their education, is an object-lesson in favour of that organisation, and public inspection, of lower-grade secondary schools which educationists have so long desired.

\section{SOCIETIES AND ACADEMIES. \\ PARIS.}

Academy of Sciences, September I3.-M. A. Chatin in the chair.-On the permanent deformation of glass, and the displacement of the zero point of thermometers, by M. L. Marchis. An application of the theory of permanent deformations, due to M. Duhem, of which an account has previously been given.-On the electrolytic separation of nickel and cobalt from iron. Application to the estimation of nickel in steel, by M. O. Ducru. The solution of the sulphates of the metals is mixed with some sulphate of ammonium and excess of ammonium hydrate, and then submitted to electrolysis. The whole of the nickel, or cobalt, is deposited, together with a trace of iron. The latter may be determined by solution of the deposit in hydrochloric acid and precipitation with ammonium hydrate, and a corresponding deduction made. Samples of steel are first dissolved in nitrohydrochloric acid, and then evaporated with excess of sulphuric acid. The test analyses given are very satisfactory.-The functions of the thyroid gland, by M. E. de Cyon. - On the respiration of Carcinus monas (Leach), by $\mathrm{M}$. Georges Bohn. The author has observed, in this species of crab, the power of reversing the direction of the circulation of water in the branchial chamber.

\section{CONTENTS.}

\section{Experimental Embryology. By Prof. W. F. R.}

Weldon, F.R.S.

Effects of High Altitude upon Man. ${ }^{\circ} \dot{F}^{\prime} \dot{P}^{\prime} \dot{W}^{\circ} 489$

Electro-Metallurgy . . . . . . . . . . . 492

Our Book Shelf:-

Hovey and Call : "The Mammoth Cave of Kentucky" 493

Bailey: "The Survival of the Unlike" ... . . 493

Linnell : "The Eye as an Aid in General Diagnosis" 493

Wilson: "The Chlorination Process ..... 494

Letters to the Editor:-

African Language. - Miss M. H. Kingsley . . . . 494

On Augury from Combat of Shell-fish. - Chas. A.

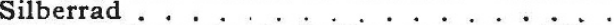

The Meudon Astrophysical observatory. (Illustrated.) By Dr. William J. S. Lockyer G Survey . . . . . . . . . . . . . . . . 496

Notes . . . . . . . . . . . 499

Our Astronomical Column :-

The Cause of the Proper Motions of Stars . . . . 504

New Determination of the Solar Constant . . . . . 504

The Diameters of Jupiter and his Satellites . . . . 504 Action of Jupiter and Saturn upon Encke's Comet : 504

Phase-Change of Light on Reflection at a Silver

Surface. (Illustrated.) By E. Edser and $\mathbf{H}$.

Stansfield
Micro-structure of Alloys. (Illustrated.)
. . . . . . .

Mechanics at the British Association . . . . 507

The Work of Pasteur and the Modern Conception

of Medicine. By Prof. Charles Richet . . . . . 508

University and Educational Intelligence . . . . 512

Societies and Academies . . . . . . . . 512 NO. 1456 , VOL. 56] 